\title{
LA OLVIDADA "NECRÓPLIS FENICIA" DE MARCHENA (SEVILLA)
}

THE FORGOTTEN “PHOENICIAN NECROPOLIS" OF MARCHENA (SEVILLA)

\author{
por \\ EDUARDO FERRER ALBELDA ${ }^{1}$
}

RESUMEN Con este artículo pretendemos relacionar algunos datos antiguos, en concreto una tumba de pozo y cámara publicada como "hipogeo fenicio" y dos esculturas aparecidas a fines del siglo XIX en las cercanías de Marchena (Sevilla), con una hipotética necrópolis cartaginesa que estaría ubicada junto a un campamento cartaginés situado en Montemolín, en el contexto de la segunda Guerra Púnica.

\begin{abstract}
In this article we seek to relate some ancient information; in this instance a pit tomb and a chamber shown as "phoenician hypogeum" and two sculptures appearing at the end of the 19th century. These sculptures were found at the outskirts of Marchena, Seville, together with a hypotetical carthaginian necropolis next to a cartaginian emcampment situated in Montemolín during the time frame of the Second Punic War.
\end{abstract}

La fecundidad arqueológica de Andalucía ha constituido, desde los albores de la Arqueología como ciencia, un reclamo para investigadores, eruditos y aventureros propios y extraños. En las últimas décadas del siglo XIX y en las primeras del XX la actividad arqueológica española, que hasta ese momento se había encauzado a través del anticuarismo y del coleccionismo, experimentó sendos procesos de institucionalización y profesionalización (Pasamar y Peiró 1987: 57 ss.; id. 1992; Peiró y Pasamar 1989-90).

En este período iniciático tiene un papel destacado en España la arqueología fenicio-púnica, bien representada en el panorama nacional a raíz de las excavaciones arqueológicas de cuatro extensas áreas funerarias: Cádiz, Los Alcores, Villaricos e Ibiza. La cultura fenicio-púnica resucitaba en España en sincronía con

1. Departamento de Prehistoria y Arqueología. Facultad de Geografía e Historia. Universidad de Sevilla. Este trabajo se encuadra en el marco del Proyecto La formación de la Bética romana, incluido en el Plan Propio de la Universidad de Sevilla, en el II Plan de Investigación de la Junta de Andalucía (HUM-152) y del Plan General de Promoción del Conocimiento (DGES PB-97-0736). 
el resto de las regiones del área mediterránea que fueron colonizadas por los fenicios, el norte de África, Cerdeña, Sicilia y Malta (Ferrer 1995: 254 ss.).

Dos de las consecuencias negativas de este "boom" fueron la acumulación desorganizada de abundante documentación en museos y colecciones particulares, y la mala digestión de los datos arqueológicos, en el sentido de que poco o nada influyeron en los planteamientos historiográficos generales, excesivamente dependientes de la arqueología filológica (Pasamar y Peiró 1987: 75; Ferrer 1996: 89). Sólo una pequeña parte de esta documentación pasó a formar parte de la llamada "cultura material" fenicio-púnica de Iberia, quedando relegados al olvido numerosos hallazgos sueltos, materiales depositados en museos y noticias hoy casi perdidas, que merecen ser incorporadas, a la luz de nuevos planteamientos, a una base de datos no demasiado amplia por sí y a todas luces incompleta.

El ejemplo que sacamos a colación es una noticia prácticamente olvidada referente al hallazgo de una "necrópolis fenicia" en Marchena (Sevilla). En los manuales de Arqueología española de los años veinte, treinta y cuarenta figuraba en el catálogo de cementerios fenicios y púnicos españoles, hasta que dejó de ser nombrada y nunca se ha vuelto a citar en obras de características similares ${ }^{2}$.

J.R. Mélida fue el primero en incorporar el dato a un inventario de necrópolis fenicias que incluía además las de Cádiz, Málaga y Carmona, diferenciándolas de las propiamente púnicas de Villaricos e Ibiza ${ }^{3}$. Posteriormente, y suponemos que a partir de los datos proporcionados por Mélida, Pericot (1934: 364) y Thouvenot (1940: 61) lo incluyeron también a sus catálogos junto a las citadas necrópolis, y, por último, García y Bellido (1942:293 n. 4 y 294) mencionó el hallazgo en su monumental obra Fenicios y Carthagineses en Occidente, utilizando como referencia la obra de Mélida. $\mathrm{Y}$ en García y Bellido debemos establecer el final de las citas ya que en obras suyas posteriores (García y Bellido 1952) desaparece el rastro, sin que se vuelva a hacer alusión alguna a la supuesta necrópolis.

La noticia inicial se remontaría algunos años antes de la publicación de Mélida, concretamente a 1917, año en el aparece un informe del autor en el Boletín de Real Academia de la Historia titulado "Antigüedades de Marchena" (Mélida 1917:319-322). La crónica hace alusión a unos descubrimientos ocurridos en Marchena y en sus alrededores referidos por el escultor marchenero Coullaut Valera, entre los que destaca un "hipogeo fenicio". El mismo Coullaut Valera exploró la construcción, tomó sus medidas y la fotografió (Ibid.: 321 , lám. III).

La descripción que hace Mélida es la siguiente: "Ocurrió al SE. (de Marchena), en un cerro de blanda arenisca al hacer un barreno, con motivo de la explotación de una cantera, pues el consiguiente movimiento de tierras dejó al descubierto un pozo cuadrado ó más bien rectangular, de $1,05 \mathrm{~m}$. de longitud en suabertura, por 0,65 á 0,70 de ancho, y de unos $12 \mathrm{~m}$. de profundidad, el cual comunica con una galería de unos cinco metros de longitud y 1,30 m. de altura, abovedada, y, al final, terminada como en ábside, estando orientada de S. á N... unos socavones pequeños prestan apoyo á los pies sirviendo de escalera,... No encontró objeto alguno, de donde debe inferirse que aquel hipogeo,..., ó fué profanado ó no llegó á usarse" ${ }^{4}$.

2. Referencias a esta supuesta necrópolis han aparecido recientemente en obras de difusión local (Alcaide 1985: 11; Millán 1996: 25).

3. "En Marchena (Sevilla) fué descubierto en un cerro de arenisca un hipogeo de pozo cuadrado, con apoyos socavados para los pies, y de $12 \mathrm{~m}$. de profundidad, a la que se encuentra la cámara, abovedada, de l'30 m. de altura y 5 de fondo, terminada en ábside; pero nada contenía." (Mélida 1929: 120-124).

4. Ibid. Hemos conservado la ortografía original del texto. 
El descubrimiento en sí no llamaría demasiado la atención ${ }^{5}$ si no fuera porque unos reglones más abajo el autor especifica que "en el mismo sitio..., fueron descubiertos hace tiempo dos importantes monumentos cartagineses: un ara con el caballo y la palmera, como se ven en las monedas de los Barquidas, y un relieve, también con palmera, y una cierva con su cervatillo".

\section{III}

El itinerario bibliográfico de estos relieves no es menos sorprendente que el del hipogeo, ya que figuran en la bibliografía arqueológica más reciente como halladas en Marchena y Osuna respectivamente (VVAA 1983: 171-172; Chapa 1985: 110-112; Olmos y otros 1992: 103; Olmos 1996: 91; VVAA 1998: 341), y, salvo en este informe de Mélida, pocas veces se han relacionado con la supuesta necrópolis fenicia.

Se desconocen sus procedencias exactas, si bien ambas piezas formaron parte de la colección del presbítero sevillano Mateos Gago en las últimas décadas del siglo XIX ${ }^{6}$. Fallecido el eminente anticuarista, la colección fue comprada por la corporación municipal sevillana (Collantes de Terán 1942: 182) y de allí pasó a formar parte de los fondos del Museo Arqueológico Provincial, donde permanecen expuestas como procedentes de Marchena y Osuna.

La primera referencia a las esculturas aparecen en la Historia de Cartago de Church (1889: 178-179), donde sólo se hace alusión al ara con caballo y palmera, proponiéndose un origen cartaginés y su relación con la simbología del dios Hammón. Años más tarde, P. Paris (1903: 326-328) las consideró púnicas, pero introdujo la primera nota de duda al vacilar entre Marchena y Osuna en la posible procedencia del segundo relieve, aunque más adelante negara explícitamente la posibilidad de un origen ursonense de la pieza.

Para Mélida (1929: 126-127) y Thouvenot (1940: 69-70) ambas proceden de Marchena, aspecto vuelto a confirmar por García y Bellido (1942: 478), si bien para el último no son monumentos púnicos sino romanos del siglo I a.C. (García y Bellido 1949: 305). Ulteriores aportaciones vuelven a equivocar la procedencia del relieve con la cierva amamantando al cervatillo, como originaria de Osuna, pero retoman las ideas de su función funeraria, de una filiación cartaginesa y, por consiguiente, de una datación centrada en el siglo III a.C. (Almagro-Gorbea y Rubio 1980: 352; Chapa 1985: 110 y 188).

Las publicaciones más recientes suelen incluirlas en catálogos de escultura ibérica, sobre todo el relieve de la cierva nodriza, quizás debido a la errónea atribución ursaonense, que ha condicionado lógicamente la adscripción cultural y cronológica al relacionarla con el resto de los relieves de Osuna. Por ello hay vacilaciones en su clasificación, pues lo mismo puede ser una pieza singular del arte ibérico de indudable significado religioso, datada en los siglos IV-III a.C. (VVAA 1983: 172), que un relieve funerario del siglo III a.C. en el que se desarrolla una imagen púnica (Olmos y otros 1992: 103), o bien una obra ibérica del siglo II a.C. con una "esquema iconográfico presente en los marfiles orientales arcaicos" (VVAA 1998: 341 ).

5. Se podría alegar que es una construcción posterior, del tipo de un aljibe por ejemplo, sobre todo si tenemos en cuenta que la galería o cámara "estaba en parte llena de agua", ibid.

6. En el Catálogo descriptivo de los objetos arqueológicos de la colección del Sr. D. Francisco Mateos Gago, presbitero (q.e.p.d.) clasificados por el Ilmo. Sr. D. Antonio Ma . Ariza y Montero-Corbacho y el Sr. D. Francisco de P. Caballero-Infante y Zuazo (Sevilla, 1891) 18, figura la relación de objetos, aunque no se describen. Pudiera tratarse del nº 76 del catálogo (Ara cartaginesa, apreciable), y del $n^{\circ} 77$ (Fragmento de alto relieve). 
Con todos estos datos hemos intentado esclarecer algunos interrogantes sobre la supuesta necrópolis. El primero es su hipotética ubicación, ya que en la referencia de Mélida sólo se señalaba su hallazgo al sureste de Marchena, en una cantera de arenisca. Todas las pesquisas seguidas en los archivos municipales de Marchena ${ }^{7}$ para localizar el lugar han sido vanas, pues no se conservan noticias sobre el hallazgo, ni referencias a explotaciones de canteras. Solamente en el mapa geológico de España ${ }^{8}$ aparecen dos canteras activas en el camino del cementerio, al sur de Marchena, y otra, todavía hoy activa, al sureste, próxima a la carretera que conduce a Puebla de Cazalla, en las cercanías del cortijo de Montemolín.

La explotación de estas canteras hasta la actualidad puede haber arrasado la supuesta necrópolis, como así ocurrió con el hipogeo. La Prospección Arqueológica Superficial del Término Municipal de Marchena ${ }^{9}$ tampoco ha aportado información alguna, aunque en las proximidades de la última cantera se ubicó probablemente la necrópolis orientalizante de Montemolín (Chaves y Bandera 1991; Chaves y otros e.p.; Bandera y otros 1993), dato que, como veremos más adelante, puede ser un indicio importante para su identificación.

Por tanto, la única posibilidad de análisis que nos queda es el estudio de las estelas y su posible relación con el hipogeo, dejando por sentado que aquellas aparecieron en el mismo lugar que la supuesta tumba, como asegura Mélida.

Con respecto al hipogeo, este tipo de enterramiento de pozo y cámara no es frecuente entre los enterramientos de época púnica de la Península Ibérica, y sólo contamos con un ejemplo de época arcaica en la tumba 1E de la necrópolis de Puente de Noy (Molina y otros 1982; Ramos 1986: 44). Su prototipos orientales se remontan al II milenio a.C. (Tejera 1979: 83) y su dispersión por el Mediterráneo central es amplia (id., 84-102). En Norteáfrica, y concretamente en Cartago, es un monumento funerario particularmente habitual. En esta ciudad este tipo de enterramiento está formado ya a fines del siglo VII o principios del VI a.C., pero su auge tiene lugar a inicios del siglo III a.C., como se documenta en la necrópolis de Santa Mónica (Benichou-Safar 1982: 354, tipo IX.1).

En lo que respecta a las esculturas, en primer lugar hay que destacar que los monumentos no son morfológicamente iguales. El primero es un cipo o estela ${ }^{10}$ en forma de ara con dos caras esculpidas en bajorrelieve, en una un caballo a la carrera, y en la otra una palmera ${ }^{11}$; y la segunda escultura no es una estela sino un sillar esculturado en altorrelieve, que probablemente formaría parte de un monumento más complejo ${ }^{12}$.

7. Agradecemos a D. Ramón Ramos su disponibilidad y amabilidad.

8. Mapa Geológico de España, Marchena Hoja 1004, 14-41. Madrid 1977.

9. Esta actividad ha sido llevada a cabo en 1999 con carácter de urgencia con la autorización de la Consejería de Cultura de la Junta de Andalucía, y bajo la dirección del que suscribe y del Dr. García Vargas, y la colaboración de la Dra. M. Oria Segura, R. Pliego, M. Ortega Gordillo, F. Cantonero, F.J. García Fernández, J. Vázquez Paz, M.A. Gavira Verdugo y M. Camacho Moreno.

10. Adoptamos la nomenclatura genérica de estela, aunque se podría haber seguido la distinción convencional entre cipo y estela establecida por P. Bartoloni para las estelas arcaicas de tofet de Cartago, entre las que distingue cipos, unos monumentos votivos que no presenta una sustancial prominencia de una de las partes respecto a las restantes, salvo algún elemento decorativo que pueda decorar una o varias de las caras, pero que no altera la estructura ni el contenido; y estelas, aquellos monumentos votivos en los que una de las caras, en forma de edícula, tiene preminencia sobre las otras mediante un encuadramiento arquitectónico, la yuxtaposición de un motivo iconográfico sobre éste, etc. (Bartoloni 1976: 27).

11. "es una ara rectangular, enmarcada por resaltes en su parte superior e inferior. La cara frontal está decorada con un caballo en relieve, en actitud de salto y representando por su lado izquierdo. El ojo se indica por incisión, y la oreja es erguida y apuntada. Las patas delanteras son cortas y delgadas, y las posteriores se dirigen hacia atrás, como la cola. El sexo está indicado. En una de las caras laterales se representa una palmera. Altura: $81 \mathrm{~cm}$.; anchura: $43 \mathrm{~cm}$; grosor $36 \mathrm{~cm}$." (Chapa 1985: 110 y 172).

12. "Caliza blanquecina. Sillar con el relieve de una cierva que da de mamar a su cría. La cierva vuelve la cabeza para comer las ramas de un árbol, quizás una palmera. Sus ojos son dos protuberancias alargadas, y el cuello largo, con una arruga determinada por la forzada postura de la cabeza. Las patas delanteras dirigidas hacia delante, están rotas y erosionadas.." Alt. 52 cm.; anchura: $37 \mathrm{~cm}$.; grosor: $11 \mathrm{~cm}$. (Chapa 1985: 110-112). 
Es importante señalar que, desde el punto de vista iconográfico, los motivos representados en ambos relieves están presentes en la iconografía funeraria cartaginesa tardía, heredados, en el caso de la palmera datilera, del repertorio egipcio a través del mundo sirio y fenicio. Hemos hecho hincapié en la procedencia cartaginesa de esta tradición iconográfica y en la cronología tardía porque, salvo los casos que estamos analizando y determinados ejemplares nortefricanos, se desconocen monumentos con este tipo de representaciones en contextos arqueológicos de época púnica de Iberia, Ibiza, Cerdeña, Sicilia y Malta; y, en lo que se refiere a la datación, las figuraciones esculpidas en ambos monumentos tampoco son habituales, por no decir inexistentes, en las estelas arcaicas del tofet de Cartago, datadas entre fines del siglo VII y el IV a.C. (Bartoloni 1976: 75-78). En este período las figuraciones características son el disco solar y el creciente lunar, el betilo, la losange, el ídolo-botella, el signo de Tanit, y, en menor proporción, la figura humana. Los motivos animales y vegetales son casi inexistentes, estando documentados solamente un delfín y una flor de loto (Ibid.: 62).

Un rápido repaso por los yacimientos púnicos de Iberia puede ser demostrativo de lo que apuntamos. Concretamente en la necrópolis púnica de Gadir (Cádiz) es habitual la señalización de las tumbas mediante estelas troncopiramidales o con simples piedras aplanadas (Belén 1992-93: 353), algo parecido a lo que ocurre en la necrópolis de Villaricos (Almería), donde predominan las representaciones anicónicas: piedras alargadas de base rectangular acabadas en punta, estelas piramidales, altares y cipos piriformes (Belén 1994).

Otros ejemplos que podemos relacionar con señalizaciones funerarias púnicas en Iberia, como los cipos en forma de ara de Riotinto (García y Bellido 1942: 294, fig. 47) y Mesas de Asta (Esteve 1950: lám. XVI), confirman la tendencia a una tipología reducida-cipos, estelas troncopiramidales, altares o simples piedrasy a la ausencia de decoraciones figuradas.

Sólo podemos mencionar una estela decorada procedente de Villaricos, con rostro humano, datada en el siglo VI a.C. (Belén 1994: 266), y otra de Cartagena, pieza realizada en un sillar donde se representa individuo togado con la mano en el pecho dentro de una hornacina (García y Bellido 1954: fig. 360). Su paralelismo con estelas similares aparecidas en La Ghorfa, de cronología tardía (posteriores al siglo III a.C.) y el hecho de que proceda de Cartagonova, una fundación cartaginesa, hacen pensar en la procedencia norteafricana tanto del difunto como de la tipología y del modelo iconográfico empleado en la estela.

Tampoco hemos encontrado paralelos iconográficos en la Sicilia púnica. En Mozia, las estelas pueden o no estar enmarcadas en edículas egiptizantes, dentro de las cuales se representan betilos-de uno a tres-, ídolos-botellas, losanges, altares, símbolos de Tanit, figuras masculinas de inspiración egipcia y, lo que es una característica que distingue a Mozia de Cartago, figuras femeninas con las manos en el pecho, desnudas o, más frecuentemente vestidas con una túnica, cuyo prototipo procede del área fenicia (Moscati y Uberti 1981; Moscati 1992: 22-23).

Las estelas de Lilibeo (siglos IV-III a.C.) siguen modelos helenísticos en sus composiciones arquitectónicas y presentan motivos tradicionales púnicos como símbolos de Tanit, caduceos, timiaterios y figuras humanas vestidas a la moda helenizante. En las estelas de época romana de este centro (siglo II a.C.-I d.C.) la decoración es típicamente grecorromana con motivos subsidiarios de tradición púnica (Moscati 1992: 28).

En el resto de las localidades púnicas de Sicilia tampoco se documentan elementos similares a los registrados en Marchena. Por ejemplo, en Selinunte, en el santuario de Zeus Meilichos, las estelas aparecidas son de forma cilíndrica, piramidal o paralepípeda, o bien toscas representaciones de una o dos cabezas sobre una estela (Moscati 1992: 29-30).

La Cerdeña púnica tampoco puede servirnos de fuente de comparación para los ejemplares de Marchena por la falta de concomitancias iconográficas y formales. Las estelas de Nora, desde el punto de vista tipológico, se pueden definir como clásicas, e iconográficamente responden al modelo egiptizante: edículas con figuraciones como betilos, disco solar y creciente lunar, losange, ídolo-botella, signo de Tanit y figuras 
masculinas y femeninas, cronológicamente situables entre los siglos VI y IV a.C. (Moscati y Uberti 1970: 25-44; Moscati 1992: 36-37).

Ocurre un fenómeno similar con las estelas de Sulcis, aún cuando éstas representen cuantitativa y cualitativamente la producción más completa del mundo púnico sardo, donde hay un número considerable de representaciones figuradas, sobre todo humanas y animales. No obstante, no aparecen esculpidos en ningún caso otros animales que no sean el carnero, en la mayoría de los casos, y el toro (sólo en dos ocasiones) ${ }^{13}$, ni motivos vegetales como la palmera. En otras localidades púnicas de Cerdeña, como Monte Sirai (Moscati 1992: 51-55) o Tharros (Moscati y Uberti 1985: 365 ss.), aparte de las peculiaridades locales, la tipología y la iconografía de las estelas responden a los modelos antes descritos.

Contrariamente, en Cartago sí encontramos estos motivos representados en estelas, constituyendo elementos iconográficos relativamente frecuentes, singularmente la palmera (Bisi 1967: figs. 12, 13, 36, 51 y 132 y fig. 77; Hours-Miédan 1950). El significado, funerario o no, de estos motivos es un debate aún abierto. Para A.Mª . Bisi (1967: 203), la palmera llena de dátiles es un emblema de fecundidad propio de las estelas púnicas, cuyo modelo remite a Egipto, y constituye un sustitutivo iconográfico de la palmeta, elemento vegetal fenicio-chipriota por excelencia. En este sentido, la palmeta es la estilización última de la palmera mesopotámica aparecida en Siria-Palestina en el II milenio a.C. (Danthine 1937: 211), de manera que en el mundo púnico cartaginés habría una vuelta a la expresión naturalista frente a la abstracción oriental.

En el Próximo Oriente la representación iconográfica de la palmera siempre estuvo relacionada con la esfera de lo sagrado. La arquitectura mesopotámica utilizó la palmera o sus partes (tronco y ramas) para diversas funciones arquitectónicas y decorativas, como las columnas de bronce en forma de tronco de palmera de Khorsabad, que flanqueaban la entrada del palacio. Asimismo la imagen de esta planta fue también incorporada a soportes menores como maquetas (Tell Halaf), estelas (Samash de Nabu-Apal-Iddina, donde el dios sol es sostenido por columnas-palmeras) o marfiles (Barnett 1954: 108-110).

Como emblema de fecundidad, la palma ha sido relacionada con los ciclos iconográficos de la diosa Isthar en Asiria, de Timmuz en Mesopotamia y de Astarté en Fenicia. En esta última región, en las cuevas de Wasta, entre Tiro y Sidón, y Adlûn, numerosos grafitos hacen referencia a la fertilidad de Astarté, representada como el triángulo púbico y la palmera (Barnett 1954: 110).

En Cartago, sin embargo, esta iconografía vegetal se relaciona frecuentemente con el ámbito funerario y con las emisiones monetales, en las que precisamente se representan juntos caballo y palmera. En el mundo de la ultratumba la palmera datilera constituiría una supervivencia del árbol sagrado, y sería alusiva a la fecundidad de la diosa. En las estelas su situación es variable, ocupando en la mayoría de las ocasiones el centro del campo; a veces aparece sola o flanqueada por dos columnas, por dos signos de Tanit, dos caduceos o dos lotos (Hours-Miédan 1950: 45). En cuanto al caballo, sobre todo el caballo rampante, al trote, se interpreta como símbolo de protección de Baal Hammon (Ibid. 1950: 59, pl. XXV).

El significado del caballo y la palmera en las monedas cartaginesas tampoco está bien establecido. La opinión más generalizada desde Müller (1860: 115-118; Marot 1993: 20) es que ambos iconos aluden al origen histórico de Cartago, teniendo como base la narración de Justino-Pompeyo Trogo (XVIII, 5). El epitomador expone que los tirios, después de un intento fallido de establecer el primer asentamiento en el que se halló el cráneo de un toro (augurio que fue interpretado como futuro de servidumbre), en un segundo intento encontraron el cráneo de un caballo bajo una palmera, hecho explicado como buen augurio, de un futuro de poder y prosperidad (Ramón 1991: 32). De esta manera, para Müller (1860: 118), la palmera, que era símbolo de los fenicios (de hecho aparece en las monedas de Tiro y de otras ciudades fenicias) designa el origen nacional de Cartago, mientras que el caballo es el emblema del país que habitan.

13. La representación de estos animales en las estelas sería alusiva a los sacrificios sustitutorios de víctimas humanas ofrecidos a Baal Hammon en el tofet (Moscati 1986: 75-79; Bartoloni 1986: tav. CXV ss.). 
No obstante, hay otras hipótesis que pretenden justificar la presencia del caballo en las monedas cartaginesas: la abundancia de caballos en Libia y la habilidad de los libios en la doma de los equinos (Herodoto IV, 93) posibilita que fuera un emblema de Libia. Asimismo se ha sugerido que entre los libiofenicios, como entre los griegos, el caballo estuviera consagrado al dios del mar, razón que se fundamenta en otro mito que narra cómo Neptuno había enseñado a los barcenos, pueblo de origen libio habitante de la Cirenaica, el arte de domar caballos (Müller 1860: 115).

Sea como fuere, caballo y palmera son iconografías íntimamente ligadas al mundo de ultratumba cartaginés. No ocurre lo mismo con el ciervo, cuya relación con la cultura semita y con los contextos funerarios es más endeble. Según Chapa (1985: 188) el relieve de la cierva de Marchena "debe ponerse en relación con el mundo religioso púnico, en el que este árbol representaba a la divinidad y a la vida, cuya renovación continua viene expresada en la existencia de la cría. En este ambiente se relacionan también el ciervo y el caballo, animal que se asocia a la palmera en las monedas cartaginesas e incluso en relieves funerarios".

Para encontrar indicios claros que relacionen a los cérvidos con los rituales funerarios fenicio-púnicos en la Península Ibérica debemos remontarnos a las figuraciones de ciervos, machos y hembras, sobre objetos litúrgicos (timiaterios) en contextos funerarios relacionados con la colonización fenicia (Bandera y Ferrer 1994; id. 1994b; id. 1995), o a las pinturas de los huevos de avestruz de Villaricos (Astruc 1951: 87 ss.), donde aparecen ciervos machos con hojas de palma (serie Ia) o un ciervo macho pastando (serie VI).

Los cérvidos, y más concretamente la cierva amamantado a una cría, no aparecen en los repertorios iconográficos de las estelas cartaginesas. No obstante, el motivo de la vaca nodriza con la cabeza vuelta si está ampliamente representado en el mundo fenicio-púnico y próximo-oriental, heredado a su vez del egipcio (Matthiae 1962: 1 ss.) y pudo servir de modelo o de inspiración iconográfica para el relieve marchenero ${ }^{14}$.

Independientemente del significado funerario que tuviesen estos animales, lo cierto es que su aparición en las cercanías de Marchena introduce interrogantes que requieren una explicación que vaya más allá de la mera búsqueda de paralelos formales. Ya hemos dejado claro que en ambos casos son elementos ajenos a la tradición arquitectónica y escultórica ibérica o iberorromana y a las costumbres funerarias púnicas de Iberia (Cádiz, Villaricos, Puente de Noy, Jardín) y de las islas del Mediterráneo central, remontándonos necesariamente al mundo funerario y monetal cartaginés posterior al siglo IV a.C. para encontrar los paralelos iconográficos más precisos. Asimismo, las tumbas de pozo y cámara tampoco se documentan en la Iberia púnica, y sí en Cartago, donde tienen su apogeo en los siglos III y II a.C.

¿Cómo explicar, pues, la existencia en un mismo contexto espacial de una tumba de pozo y cámara, de una estela y de otro monumento funerario de tales características en plena campiña sevillana?.

Creemos que estos hallazgos deben contextualizarse en el marco de los enfrentamientos entre Cartago y Roma durante la segunda Guerra Púnica. Es bien sabido que el valle del Guadalquivir fue uno de los principales escenarios de las hostilidades entre cartagineses y romanos, y que la última y decisiva batalla, la de Ilipa, que puso fin a la presencia cartaginesa en la Península Ibérica, debió librarse en esta zona, concretamente entre Carmona y Marchena (Corzo 1975: 238). Asimismo, la existencia de un fuerte componente cartaginés en Carmona ha sido puesta de manifiesto reiteradamente (Bendala 1976; id. 1982; id. 1994).

La evidencia arqueológica de estos contingentes cartagineses ha sido documentada -entre otros asentamientos-en Montemolín, donde F. Chaves (1990: 620-621) sitúa un campamento cartaginés que ha definido como el centro de apoyo de las fuerzas militares cartaginesas más importante de Andalucía occidental.

14. Agradecemos a la Profra. Dra. Marín Ceballos la orientación bibliográfica que nos ha prestado. 
El yacimiento ha proporcionado una gran cantidad de moneda hispano-cartaginesa y de otras procedencias encuadrables en el ambiente de la circulación monetaria de fines del siglo III a.C. (Collantes 1980; Villaronga 1981; Chaves 1990: 620), y las excavaciones arqueológicas llevadas a cabo en la acrópolis del conjunto arqueológico sugieren una reocupación de este espacio, coetánea a estos acontecimientos (García y otros 1989: 240; Bandera y otros 1993: 32).

Además de los hallazgos numismáticos, la situación geoestratégica del asentamiento hace comprensible la atribución de su función como campamento cartaginés y su papel protagonista en la contienda romanocartaginesa: es una atalaya desde donde se divisa Carmona, Osuna y Marchena, en un radio de unos 20 kms.; y está situada a orillas del río Corbones, en una encrucijada de caminos que comunicaban el Bajo Guadalquivir con la Alta Andalucía, a través de la llamada "Vía Ibérica" o "de las Torres de Aníbal" (Corzo y Toscano 1992: 132), y la costa mediterránea con el valle del Guadalquivir (Bandera y otros 1993: 31 ).

El hecho de que en Montemolín se instalara un campamento permanente, y probablemente una ceca itinerante (Chaves 1990: 630), induce a pensar que debió surgir la necesidad por parte de la población de un espacio reservado para los difuntos. En este sentido, ya hemos comentado que la necrópolis del Montemolín orientalizante está situada en un cerro cercano al yacimiento, junto a una cantera de arenisca explotada en la actualidad; y que el hipogeo y las estelas se hallaron en una cantera de arenisca al sureste de Marchena.

Nuestra hipótesis, una vez sopesados todos estos datos, sería que tanto la tumba de pozo y cámara como la estela y el relieve pertenecieron al área funeraria del campamento cartaginés, el cual debió tener una vida corta pues la derrota definitiva del ejército cartaginés en el 206 a.C. acabó sin duda con el campamento púnico. El núcleo de población turdetano continuó su vida en un cerro parejo llamado Vico (Chaves y Bandera 1987). Curiosamente la necrópolis del campamento cartaginés se ubicó junto a la necrópolis del poblado del período orientalizante, de la misma manera que el campamento se había levantado sobre la antigua acrópolis edificada con construcciones "singulares" de evidente influencia oriental, una de ellas identificada con un edificio sacrificial (Bandera y otros 1999: 216; Chaves y otros e.p.).

En definitiva, con estas líneas hemos pretendido incorporar estos datos olvidados y descontextualizados -no en el sentido estratigráfico del término, sino en el histórico-arqueológico-a un debate que lleva muchos años estancado y que precisa una revisión urgente.

\section{BIBLIOGRAFÍA}

ALCAIDE AGUILAR, F. (1985): Guía básica histórico-artística de Marchena. Marchena.

ALMAGRO-GORBEA, M. y RUBIO, F. (1980): “El monumento ibérico de 'Pino Hermoso'. Orihuela (Murcia)". TP 37: 345-362.

BANDERA, Mª.L. de la; CHAVES, F.; ORIA, M.; FERRER, E.; GARCÍA, E. y MANCEBO, J. (1993): "Montemolín. Evolución del asentamiento durante el Bronce Final y el Período Orientalizante (campañas de 1980 y 1981)", AAC 4: 15-48. Córdoba.

BANDERA, Ma.L. de la y FERRER, E. (1994a): "El timiaterio orientalizante de Villagarcia de la Torre (Badajoz)", AEspA 67: 41-61. Madrid.

(1994b): "Thymiateria orientalizantes en bronce. Nuevas aportaciones y consideraciones", Homenaje al Profesor Presedo: 43-60. Sevilla.

(1995): "Reconstrucción del ajuar de una tumba de Cástulo: ¿indicios de mestizaje?”, Kolaios 4: 53-65. (1998): "Indicios de carácter económico y ritual de tradición próximo-oriental en el sur de Iberia" Actas del Congreso "El Mediterráneo en la Antigüedad: Oriente y Occidente". Sapanu. Publicaciones en Internet II [http://www.labherm.filol.csic.es]. 
BANDERA, Ma . de la; CHAVES, F. y FERRER, E. (1999): "Sacrificio, ganado y manipulación de carnes. Una propuesta aplicada al período orientalizante", II Congreso de Arqueología Peninsular. III: 213-219. Alcalá de Henares.

BARNETT, R.D. (1954): A Catalogue of the Nimrud Ivories. London.

BARTOLONI, P. (1976): Le stele arcaiche del tofet di Cartagine. Roma.

(1986): Le stele di Sulcis. Catalogo. Roma.

BELÉN, Ma . (1992-93): "Religiosidad funeraria en la necrópolis prerromana de Cádiz", Tabona VIII, II: 351-364. Tenerife.

(1994): “Aspectos religiosos de la colonización fenicio-púnica en la Península Ibérica. Las estelas de Villaricos (Almería)", Spal 3: 257-279.

BENDALA, M. (1976): La necrópolis romana de Carmona (Sevilla). Sevilla.

- (1982): "La perduración púnica en los tiempos romanos: el caso de Carmo", Huelva Arqueológica VI: 193-203. Huelva.

- (1994): "El influjo cartaginés en el interior de Andalucía", Cartago, Gadir, Ebusus y la influencia púnica en los territorios hispanos. VII Jornadas de Arqueología Fenicio-púnica: 59-74. Ibiza.

BISI, A.M". (1967): "Le stele puniche" Studi Semitici 27. Roma.

CHAPA, T. (1985): Escultura ibérica zoomorfa. Madrid.

CHAVES, F. (1990): "Los hallazgos numismáticos y el desarrollo de la segunda guerra púnica en el sur de la Península Ibérica", Latomus XLIX, 3: 613-622. Bruxelles.

CHAVES, F. y BANDERA, M".L. de la (1987): "Excavaciones arqueológicas en el cortijo de Vico", $A A A$ 1985 III: 372-379.

(1991): "Aspectos de la urbanística en Andalucía occidental en los siglos VII-VI a.C. a la luz del yacimiento de Montemolín (Marchena, Sevilla)" Atti del II Congresso Internazionale di Studi Fenici e Punici II: 691-714. Roma.

CHAVES, F.; BANDERA, M‥L. de la; FERRER, E. y BERNÁLDEZ, E. (e.p.): "El complejo sacrificial de Montemolín" Actas del IV Congreso Internacional de Estudios Fenicios y Púnicos. Madrid.

CHURCH, J. (1889): Historia de Cartago, versión española, con ampliaciones y notas de Francisco Fernández y González. Madrid.

COLLANTES, E. (1980): "Muestra de divisores hispano-cartagineses hallados en Montemolín (Sevilla)", Acta Numismática X: 29-39.

COLLANTES DE TERÁN, F. (1942): "La colección arqueológica municipal de Sevilla" Memorias de los Museos Arqueológicos Provinciales. Madrid.

CORZO SÁNCHEZ, R. (1975): "La segunda guerra púnica en la Bética”, Habis 6: 213-240. Sevilla.

CORZO, R. y TOSCANO, M. (1992): Las vías romanas de Andalucía. Sevilla.

DANTHINE, H. (1937): La palmier-dattier et les arbres sacrés dans l'iconographie de l'Asie occidentale ancienne. Paris.

ESTEVE GUERRERO, M. (1950): "Excavaciones en Asta Regia (Mesas de Asta, Jerez). Campaña de 1945-46", Informes y Memorias 22. Madrid.

FERRER ALBELDA, E. (1995): Los púnicos en Iberia: Análisis historiográfico y arqueológico de la presencia púnica en el sur de la península ibérica. Tesis Doctoral inédita. Sevilla.

(1996): La España cartaginesa. Claves historiográficas para la historia de España. Sevilla.

GARCÍA, E.; MORA, M. y FERRER, E. (1989): "Estudios sobre cerámicas ibéricas andaluzas : Montemolín (Marchena, Sevilla)", Habis 20: 217-243. Sevilla.

GARCÍA Y BELLIDO, A. (1942): Fenicios y Carthagineses en Occidente. Madrid.

- (1949): Esculturas romanas de España y Portugal. Madrid.

(1952): Historia de España. Protohistoria II. La colonización cartaginesa desde sus comienzos (fundación de Ibiza, 654) hasta la conquista cartaginesa (237). Madrid. 
HOURS-MIÉDAN, M. (1950): “Les représentations figurées sur les stèles de Carthage", Cahiers de Byrsa I: 15-60.

MAROT, T. (1993): "Introducción a la Numismática antigua: el ejemplo de la moneda en el mundo púnico", Numismática hispano-púnica. Estado actual de la investigación. VII Jornadas de Arqueología feniciopúnica: 9-25.

MATTHIAE, P. (1962): "Il motivo della vacca cha allatta nell'iconografia del Vicino Oriente antico", Rivista degli Studi XXXVII, I-II: 1-31.

MÉLIDA, J.R. (1917): “Antigüedades de Marchena”, BRAH LXX: 319-322. Madrid.

- (1929): Arqueología Española. Barcelona.

MILLÁN LEÓN, J. (1996): "Protohistoria de Marchena y su entorno", Actas de las I Jornadas sobre Historia de Marchena I, 17-35. Sevilla.

MOLINA, F.; RUIZ, A. y HUERTAS, C. (1982): Almuñécar en la Antigüedad. La necrópolisfenicio-púnica de Puente de Noy I. Granada.

MOSCATI, S. (1986): Le stele di Sulcis. Caratteri e confronti. Roma (1992): Le stele puniche in Italia. Roma.

MOSCATI, S. y UBERTI, Ma..L. (1970): Le stele púniche di Nora. Roma.

(1981): Scavi a Mozia-Le stele I. Roma.

(1985): Scavi al tofet di Tharros. I monumenti lapidei. Roma.

MÜLLER, L. (1860): Numismatique de L'Ancienne Afrique. Bologna (ed. 1964).

OLMOS ROMERA, R. (1996): "Signos y lenguajes en la escultura ibérica. Lecturas conjeturales" en R. Olmos (ed.) Al otro lado del espejo: Aproximación a la imagen ibérica: 85-98. Madrid.

OLMOS, R.; TORTOSA, T. e IGUÁCEL, P. (1992): "Catálogo" La sociedad ibérica a través de la imagen: 33-168. Madrid.

PARIS, P. (1903): Essai sur l'art et l'industrie de l'Espagne primitive I. Paris.

PASAMAR, G. y PEIRÓ, I. (1987): Historiografía y práctica social en España. Zaragoza.

— (1992): “Los orígenes de la profesionalización historiográfica española sobre Prehistoria y Antigüedad (tradiciones decimonónicas e influencias europeas)" Historiografía de la Arqueología y de la Historia Antigua en España (siglos XVIII-XX): 73-77. Madrid.

PEIRÓ, I. y PASAMAR, G. (1989-90): "El nacimiento en España de la Arqueología y la Prehistoria (Academicismo y Profesionalización, 1856-1936)", Kalathos 9-10: 9-30.

PERICOT, L. (1934): Historia de España. Gran Historia General de los pueblos hispánicos. La España Antigua-Protohistoria. Barcelona.

RAMÓN TORRES, J. (1991): "Cartago, su función y su carácter inicial”, La caída de Tiro y el auge de Cartago. V Jornadas de Arqueología fenicio-púnica, 29-45. Ibiza.

RAMOS SAINZ, Ma.L. (1986): Estudio sobre el ritual funerario en las necrópolis fenicias y púnicas de la Península Ibérica. Madrid.

TEJERA GASPAR, A. (1979): Las tumbas fenicias y púnicas del Mediterráneo. Estudio tipológico. Sevilla. THOUVENOT, R. (1940): Essai sur la province romaine de Betique. Paris.

VILLARONGA, L. (1981): "Hallazgo de cuatro dracmas de Arse de cabeza de Pallas en Montemolín", Saguntum 16: 247 ss.

VVAA (1983): Los Iberos. Madrid.

VVAA (1998): Los Iberos: Príncipes de Occidente. Catálogo de la Exposición. Barcelona. 


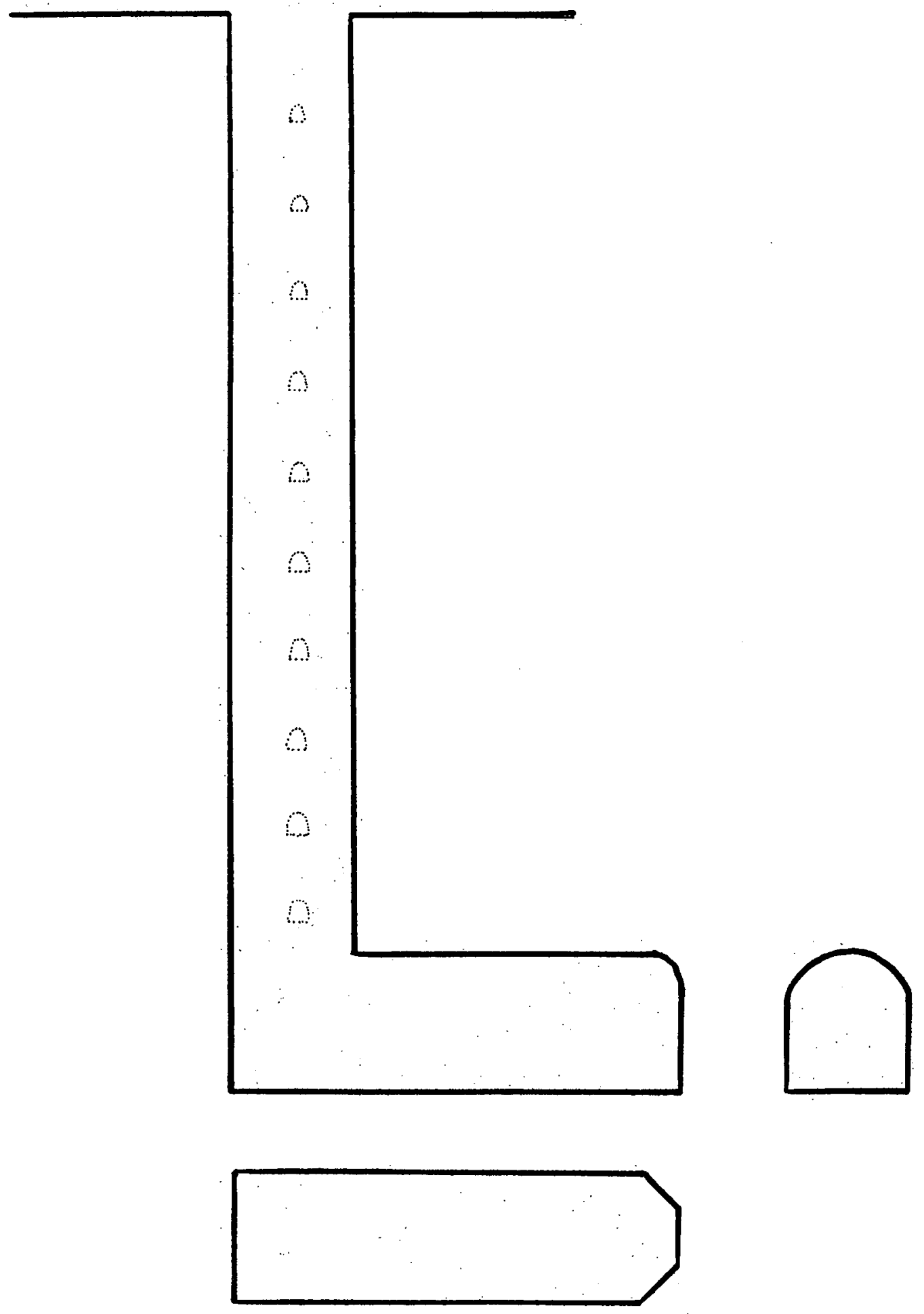

Fig. 1. Reconstrucción hipotética de la tumba de pozo y cámara de Marchena. 


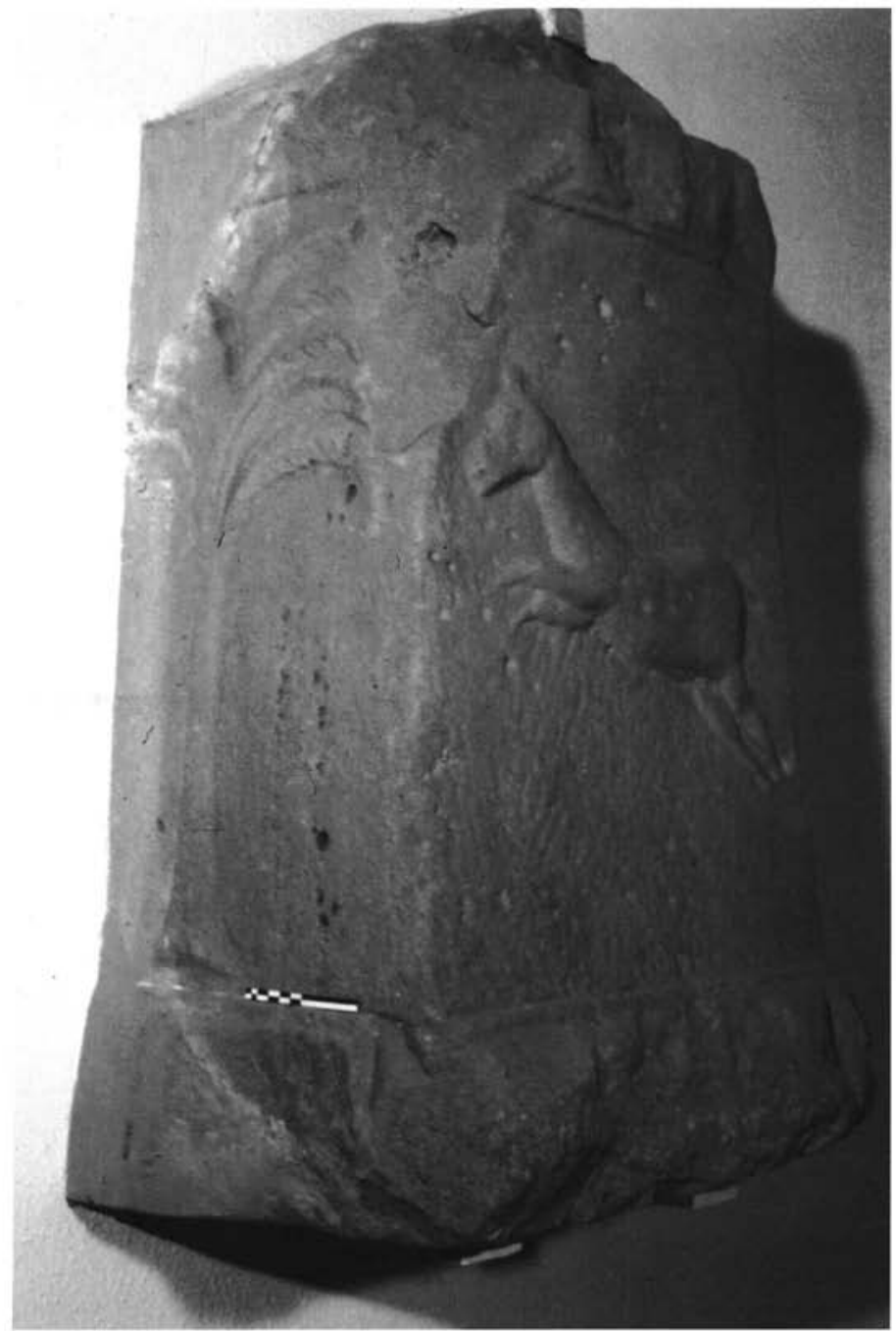

Lámina I. Estela de Marchena (foto F. Quesada Sanz) 


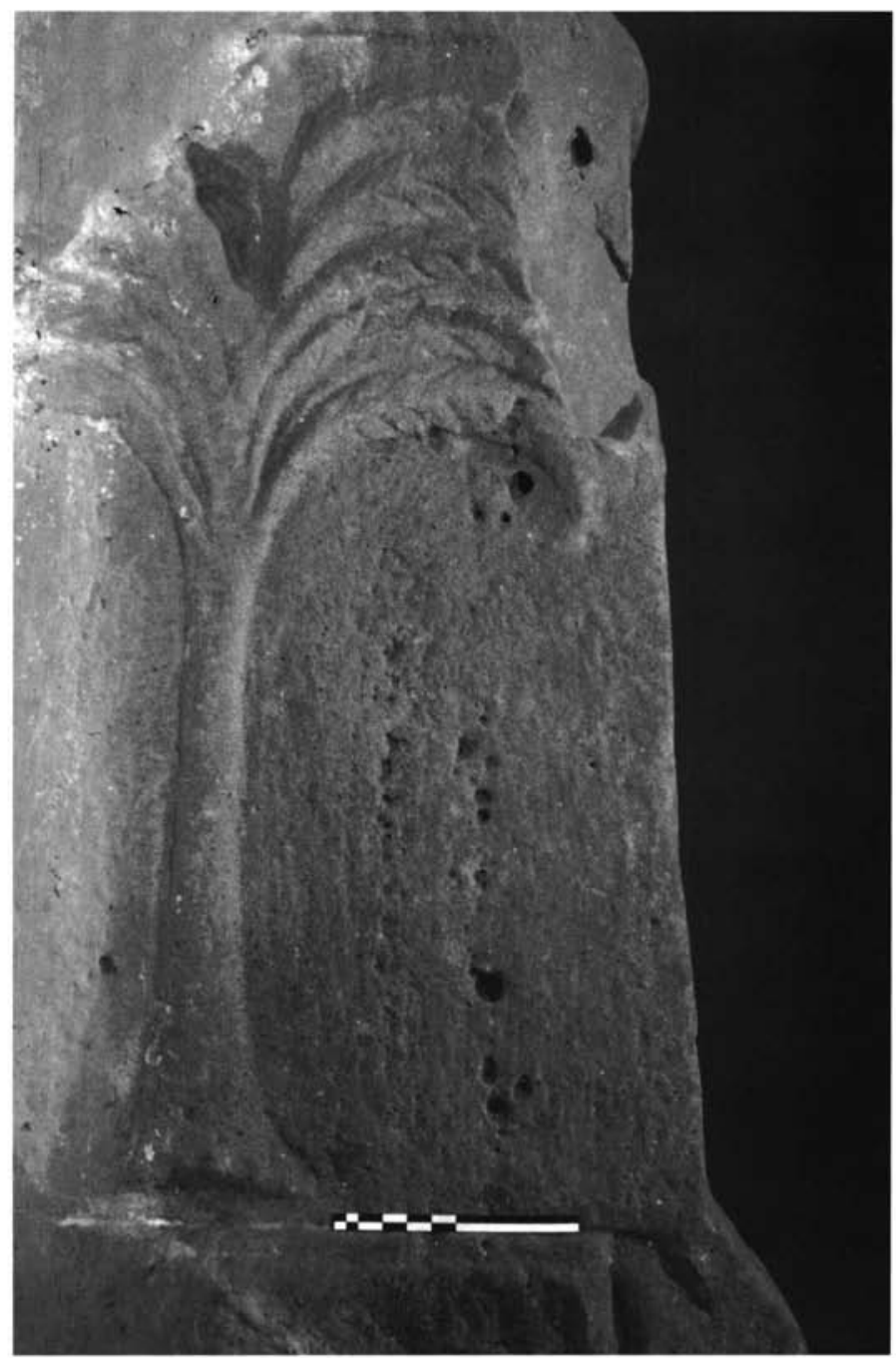

Lámina II. Estela de Marchena, detalle (foto F. Quesada Sanz). 


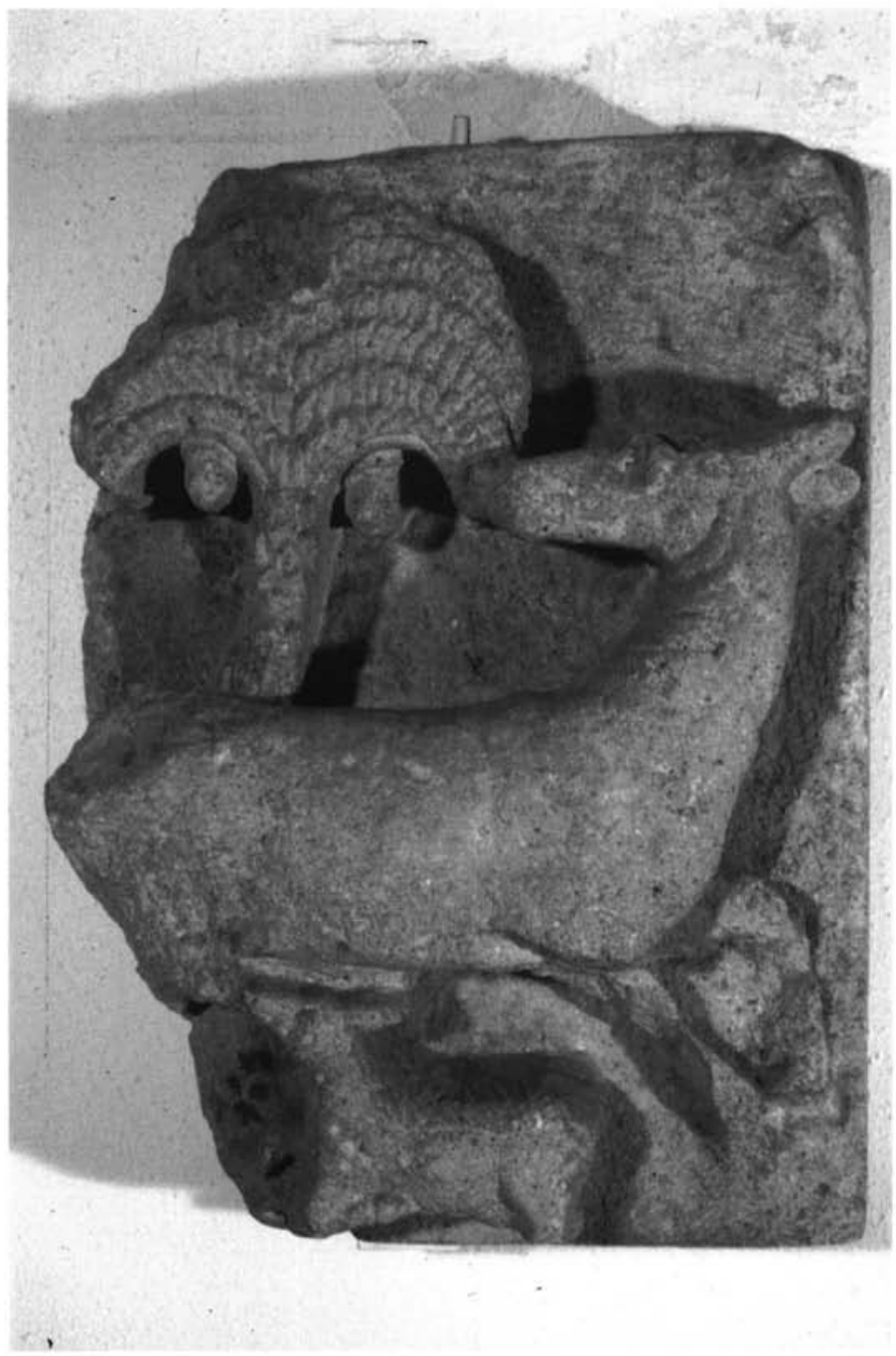

Lámina III. Altorrelieve de Marchena (foto F. Quesada Sanz). 